\title{
Reduction behavior and catalytic properties of cobalt containing ZSM-5 zeolites
}

\author{
Sung-Jeng Jong, Soofin Cheng * \\ Department of Chemistry, National Taiwan University, Taipei 107, Taiwan, R.O.C.
}

Received 19 April 1994; revised 24 November 1994; accepted 10 January 1995

\begin{abstract}
The reduction behaviors and catalytic properties of cobalt containing ZSM- 5 zeolites prepared by various methods were compared. Temperature-programmed reduction (TPR), X-ray diffraction and IR spectroscopy were the main techniques used for the study of reduction behavior. The existence of framework cobalt and small amounts of cobalt oxide in Co-ZSM-5 samples, which were prepared by incorporation of different amounts of cobalt into the zeolite synthesis gels, and cobalt silicate-like species in the Co/ZSM- 5 sample, which was prepared by precipitating impregnation of cobalt oxide on ZSM-5, were therefore established. TPR studies indicated that both framework cobalt and cobalt silicate-like species required temperatures higher than $973 \mathrm{~K}$ to be reduced. The structure of $\mathrm{Co}-\mathrm{ZSM}$ 5 was partially destroyed after reduction at temperatures higher than $1023 \mathrm{~K}$, due to the removal of framework cobalt from the ZSM-5 structure. On the other hand, the reduction of cobalt silicate-like species in Co/ZSM-5 at $1023 \mathrm{~K}$ did not affect the zeolitic structure. As the cobalt loading in CoZSM-5 was increased, increasing amounts of extra-framework cobalt oxide were formed and well dispersed in the porous structure of zeolite. The catalytic activities of these cobalt-containing zeolites in carbon monoxide hydrogenation were found to be directly proportional to the amount of cobalt metal present. The latter was obtained from the reduction of cobalt oxide under pretreatment conditions. The acidity and shape selectivity of ZSM-5 accounted for the product selectivity.
\end{abstract}

Keywords: Carbon monoxide hydrogenation; Cobalt-ZSM-5; Reduction; Temperature-programmed reduction; $\mathrm{X}$-ray diffraction; Zeolites

\section{Introduction}

Metal containing zeolites have been used as catalysts for a wide range of chemical reactions, such as hydrogenation, oxidation, isomerization, and cracking of various organic feedstocks [1,2]. Possible applications of these materials in various chem-

* Corresponding author. E-mail chem1031@ccms.ntu.edu.tw, fax. (+ 886-2) 3636359. 
ical industrial processes have attracted considerable interest to investigate these systems. Furthermore, a combination of a Fischer-Tropsch metal, such as iron or cobalt, with ZSM-5 zeolite has resulted in bifunctional catalysts. These catalysts were found to exhibit improved selectivity for gasoline-range products, and therefore synthesis gas can be converted to gasoline-range hydrocarbons in one step [35].

The catalytic activity and selectivity of bifunctional catalysts were reported to be affected by the preparation methods. Rao and Gromley [5] compared the activities of cobalt-ZSM-5 catalysts prepared by two different methods and found that the selectivity to aromatics was higher with the catalyst prepared by methods of physically admixing. The lower selectivity to aromatics with the catalysts prepared by impregnation was attributed to the decrease in the number of Brønsted acid sites in the zeolites and a result of some cobalt in an ion-exchanged form.

By dispersing transition metals within the zeolite pore structures, a well dispersed metal phase is usually expected because the particle size of the metal will be limited to the pore dimensions. As a result, the catalytic behavior of the supported catalyst is expected to be different from those with chunks of metals $[2,6]$. In the literature, several methods have been investigated to prepare cobalt containing zeolites [ $7-$ 9]: (1) decomposition of organometallic compounds on zeolites, (2) impregnation of zeolite with cobalt nitrate solution, (3) ion-exchange, and (4) incorporation of cobalt ions within zeolites during crystal growth. Rossin et al. [9] have reported different ways to incorporate cobalt into the ZSM-5 structure during the crystal growth procedure. By adding a cobalt containing amorphous aluminosilicate into the ZSM-5 synthesis gel, they obtained cobalt isomorphously substituted zeolites of high crystallinity. However, it was also found that these cobalt-ZSM-5 crystals had low activity in carbon monoxide hydrogenation.

The aim of this study is to identify the location and chemical nature of the cobalt species in cobalt containing ZSM-5 zeolites prepared by two different methods: (1) incorporation of cobalt in the zeolite synthesis gel, and (2) precipitating impregnation of a cobalt salt on zeolite crystals, and to elucidate their catalytic behaviors in carbon monoxide hydrogenation based on the characterization results.

\section{Experimental}

\subsection{Synthesis}

ZSM-5 zeolite with a Si/Al mole ratio of 140 was prepared according to the procedures described in the literature [10]. The molar composition of the gel was $10 \mathrm{Na}_{2} \mathrm{O}-20 \mathrm{TPABr}-\mathrm{Al}_{2} \mathrm{O}_{3}-950 \mathrm{SiO}_{2}-5300 \mathrm{H}_{2} \mathrm{O}$, where TPABr is tetrapropylammonium bromide. The as-synthesized zeolite was calcined at $823 \mathrm{~K}$ in air for 12 $16 \mathrm{~h}$ to decompose the TPA ${ }^{+}$ions, followed by $\mathrm{NH}_{4}^{+}$-exchange with a $1 \mathrm{M} \mathrm{NH}_{4} \mathrm{Cl}$ 
solution four times. The proton form of ZSM-5 (H-ZSM-5) was obtained by calcining the ammonium form of ZSM-5 at $823 \mathrm{~K}$ for $12-16 \mathrm{~h}$.

Co-ZSM-5 catalysts were prepared by adding a solution of cobalt sulfate into the aqueous mixture of water glass ( $\mathrm{Si}$ source), $\mathrm{TPABr}$ and $\mathrm{NaOH}$, followed by adjusting the $\mathrm{pH}$ value of the solution to 11 with sulfuric acid, and autoclaving at $453 \mathrm{~K}$ for two days. The samples in acid form were obtained through treatment similar to that mentioned for the preparation of H-ZSM-5. The Si/Co mole ratio was varied from 10,40 , to 80 based on the starting components.

A sample (termed Co/ZSM-5), with cobalt oxide impregnating precipitation on zeolite in a $1: 10$ weight ratio, was prepared by adding a $1 \mathrm{M} \mathrm{Na}_{2} \mathrm{CO}_{3}$ solution into a H-ZSM-5 zeolite suspension in hot $(358-363 \mathrm{~K})$ cobalt nitrate solution until a $\mathrm{pH}$ of 9.5 was reached. The solid was filtered, washed and calcined at $823 \mathrm{~K}$, followed by ammonium ion-exchange again with $\mathrm{NH}_{4} \mathrm{Cl}$ solution and calcination to ensure that the zeolite was in the proton form.

\subsection{Characterization}

X-ray powder diffraction patterns were obtained using a Philips 1840 X-ray diffractometer with $\mathrm{Cu} \mathrm{K} \alpha$ radiation. The lattice parameters were determined with a Mac Science MXP3T X-ray diffractometer. The transmission IR spectra were obtained using $\mathrm{KBr}$ mixed pellets with a Perkin-Elmer 983 spectrometer. The diffuse reflectance spectra were taken with self-sustained wafers after heating at $673 \mathrm{~K}$ for $2 \mathrm{~h}$ to examine the $\mathrm{OH}$ stretching vibration using a Bomem MB155 FTIR spectrometer. Surface area measurement was based on the physical adsorption of nitrogen at $77 \mathrm{~K}$ using a volumetric system. Silicon and cobalt contents were determined by ICP-AES (Allied analytical systems, Model ICAP 9000) analysis on the dissolved samples.

Temperature-programmed reduction experiments were carried out in a homebuilt device. The reactor, consisting of a $1 / 4$ in. O.D. quartz tube, was surrounded by a programmable furnace. A thermocouple placed directly in the sample bed was used to monitor continuously sample temperature. A sample of $100 \mathrm{mg}$ was dried and degassed under dry nitrogen at $473 \mathrm{~K}$, cooled to ambient temperature, followed by heating at a programmed rate of $10 \mathrm{~K} / \mathrm{min}$ to $1113-1173 \mathrm{~K}$ in a $10 \% \mathrm{H}_{2} / \mathrm{N}_{2}$ gas flow. The $\mathrm{H}_{2} / \mathrm{N}_{2}$ mixture gas was purified by passing through a copper based oxygen removal catalyst (BASF R3-11), followed by a molecular sieve trap. The flow-rates of the gases were monitored by mass flow controllers and meters. The flux of $\mathrm{H}_{2} / \mathrm{N}_{2}$ gas was maintained at a flow-rate of $25 \mathrm{~cm}^{3} / \mathrm{min}$. Hydrogen consumption was detected with a thermal conductivity detector (TCD), where the $\mathrm{H}_{2}$ / $\mathrm{N}_{2}$ gas passed through the reference cell, forward to reactor and trap, then back to the sample cell of the TCD. A liquid- $\mathrm{N}_{2}$-acetone trap, which was kept at a temperature of ca. $193 \mathrm{~K}$, was placed at the out-stream of the reactor and was used for the removal of water formed during the temperature-programmed reduction (TPR) experiment. 
Table 1

Elemental analysis data and BET surface areas of cobalt containing ZSM-5 zeolites

\begin{tabular}{|c|c|c|c|c|}
\hline \multirow[t]{2}{*}{ Samples } & \multicolumn{2}{|c|}{$\mathrm{Si} / \mathrm{Co}(\mathrm{mol}$ ratio $)$} & \multirow[t]{2}{*}{$\mathrm{Si} / \mathrm{Al}$ (mol ratio) solid } & \multirow[t]{2}{*}{ BET S.A. $\left(\mathrm{m}^{2} / \mathrm{g}\right)$} \\
\hline & Gel & Solid & & \\
\hline Co-ZSM-5/CP(10) & 10 & 5.4 & 117 & 374 \\
\hline Co-ZSM-5/CP(40) & 40 & 27 & 150 & 385 \\
\hline Co-ZSM-5/CP(80) & 80 & 57 & 126 & 386 \\
\hline H-ZSM-5 & & & 140 & 366 \\
\hline $\mathrm{Co} / \mathrm{H}-\mathrm{ZSM}-5 / \mathrm{IP}$ & & & 140 & 301 \\
\hline
\end{tabular}

Temperature-programmed desorption (TPD) of ammonia was carried out with a DuPont 9900 thermogravimetric system. The catalyst was preheated at $823 \mathrm{~K}$ under dried nitrogen gas for $30 \mathrm{~min}$, then cooled to ambient temperature for ammonia adsorption. After purging the physically adsorbed ammonia at $473 \mathrm{~K}$, the TPD profile was obtained by heating the catalyst bed to $873 \mathrm{~K}$ at a heating rate of $10 \mathrm{~K} /$ $\min$.

\subsection{Reaction}

The catalyst was reduced with a $10 \% \mathrm{H}_{2} / \mathrm{N}_{2}$ gas flow $(25 \mathrm{ml} / \mathrm{min}$ ) at $673 \mathrm{~K}$ for 16-20 h. Then, the temperature of the catalyst was lowered to reaction temperature $(573 \mathrm{~K})$ under the $\mathrm{H}_{2} / \mathrm{N}_{2}$ atmosphere. The reactant gas $\left(\mathrm{H}_{2} / \mathrm{CO}=1\right)$ was introduced and the pressure was slowly raised to $50 \mathrm{~atm}$. A flow of $20 \mathrm{ml} / \mathrm{min}$ (under 1 atm) was maintained.

The products of the reaction were hydrocarbons, carbon dioxide and water. The liquid products were collected in a stainless steel tubular trap at room temperature under $50 \mathrm{~atm}$, while the gaseous products and the unconverted feed gases were analyzed periodically using an on-line gas chromatograph. The liquid products collected in the first $8 \mathrm{~h}$ were abandoned since the Fischer-Tropsch reaction had a long induction period.

\section{Results and discussion}

Table 1 shows the BET surface areas and the elemental analysis results of CoZSM-5 samples with various cobalt loadings. The cobalt content in the solid is less than, but directly proportional to, that in the preparation gel, while the Al contents are in the range close to that of plain ZSM-5. They all have comparably high surface areas as that of H-ZSM-5. The color of the as-synthesized samples was pink to pale purple, but that turned to dark yellow after calcination at $823 \mathrm{~K}$ for $16-20 \mathrm{~h}$. Because bulk cobalt oxide $\left(\mathrm{Co}_{3} \mathrm{O}_{4}\right)$ is black, the dark yellow color suggests that the samples might contain some extra-framework cobalt oxide. Table 2 lists the lattice para- 
Table 2

Lattice parameters of cobalt containing ZSM-5 zeolites prepared by co-precipitation

\begin{tabular}{llllll}
\hline Samples & $a$ & $b$ & $c$ & $\beta$ & Volume \\
\hline Co-ZSM-5/CP(10) & 19.874 & 20.108 & 13.371 & 90.65 & 5342.9 \\
Co-ZSM-5/CP(40) & 19.874 & 20.105 & 13.370 & 90.66 & 5342.0 \\
Co-ZSM-5/CP(80) & 19.894 & 20.103 & 13.366 & 90.72 & 5345.0 \\
H-ZSM-5 & 19.880 & 20.107 & 13.369 & 90.65 & 5343.6 \\
\hline
\end{tabular}

monoclinic structure, length unit in ångstrom.

meters obtained from the powder X-ray diffraction patterns of Co-ZSM-5 samples, in comparison to those of H-ZSM-5. The data show that the lattice parameters as well as the unit cell volumes do not vary in a consistent pattern with the cobalt loading. These results are attributed to the disorder of lattice structures and decrease in crystallinity of these co-precipitated samples as the cobalt loading increases. However, the presence of cobalt ions in the framework was confirmed by the appearance of an extra absorption peak in the O-H stretching vibration region. Fig. 1 shows that $\mathrm{H}-\mathrm{ZSM}-5$ gives two peaks at 3598 and $3728 \mathrm{~cm}^{-1}$, corresponding to

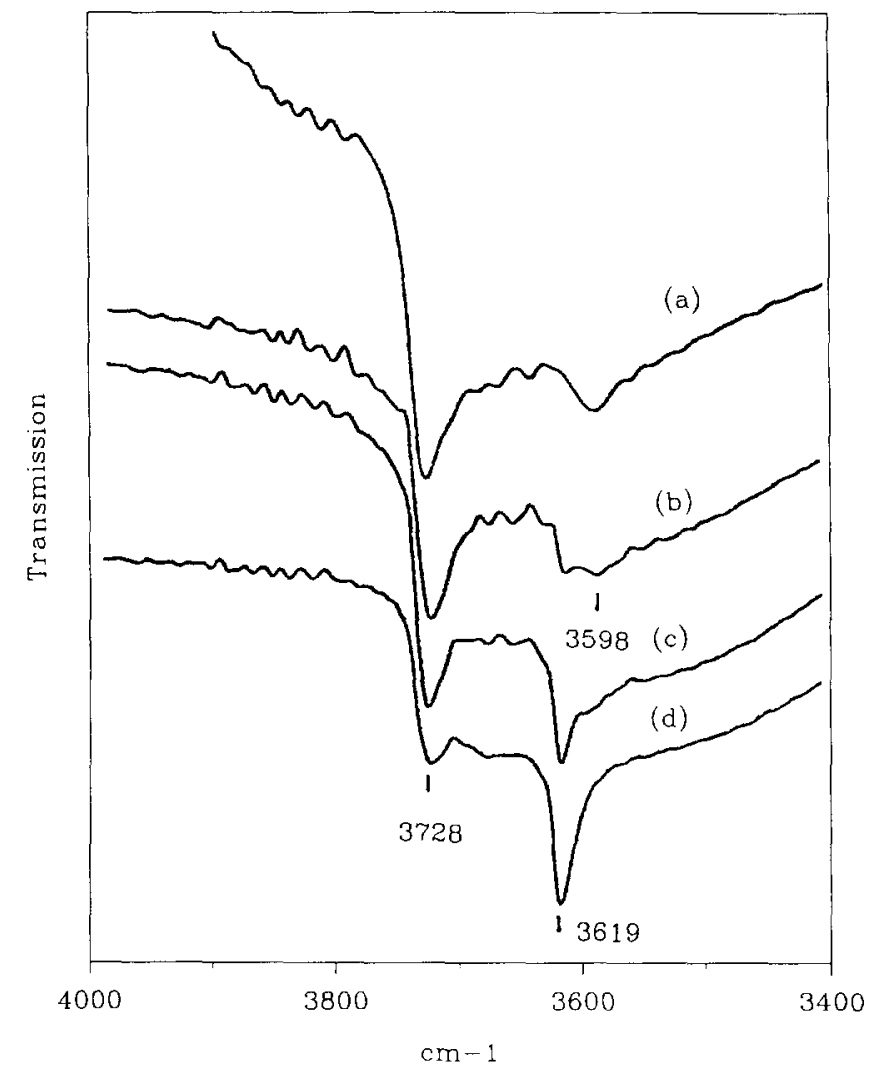

Fig. 1. Diffuse reflectance IR spectra of the OH stretching vibration region of H-ZSM-5 (a), and Co-ZSM-5 catalysts of $\mathrm{Si} / \mathrm{Co}=57$ (b), $\mathrm{Si} / \mathrm{Co}=27$ (c), and $\mathrm{Si} / \mathrm{Co}=5.4$ (d). 


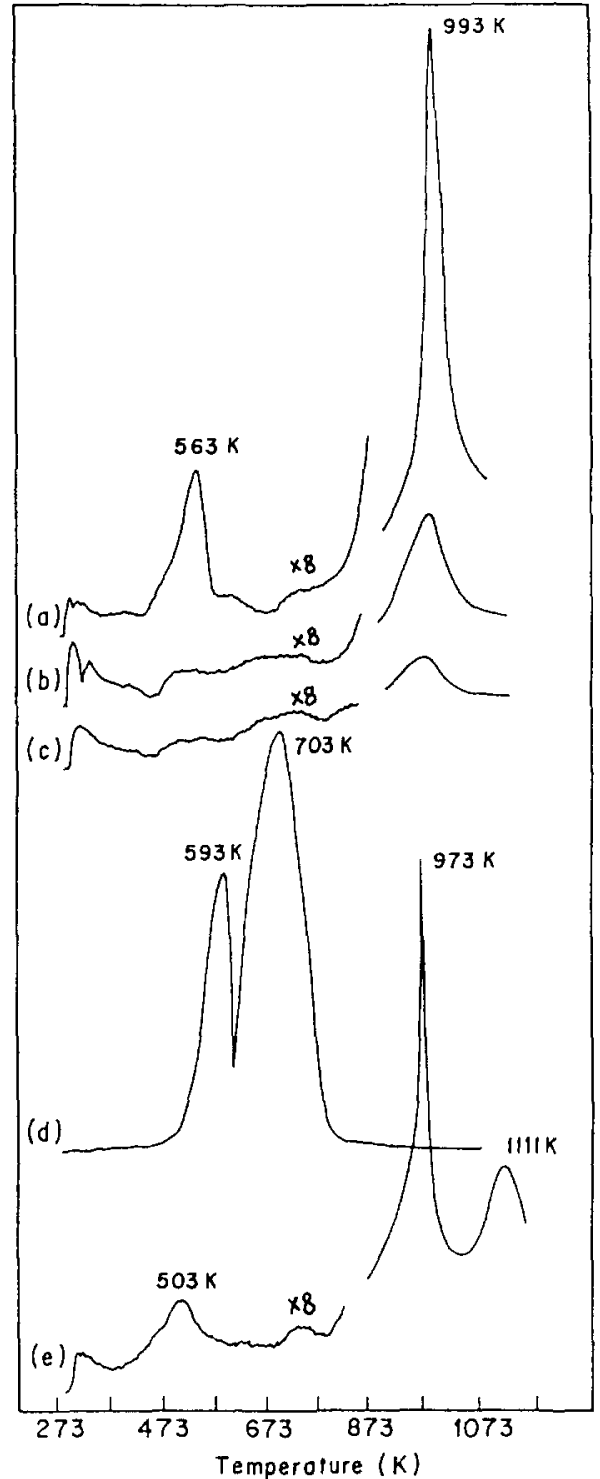

Fig. 2. TPR profiles of Co-ZSM-5 ( $\mathrm{Si} / \mathrm{Co}=5.4)$ (a), Co-ZSM-5 ( $\mathrm{Si} / \mathrm{Co}=27)(\mathrm{b}), \mathrm{Co}-\mathrm{ZSM}-5(\mathrm{Si} / \mathrm{Co}=56$ ) (c), $\mathrm{CO}_{3} \mathrm{O}_{4}$ (d), and $\mathrm{Co} / \mathrm{ZSM}-5$ (e)

the $\mathrm{O}-\mathrm{H}$ groups adjacent to framework with $\mathrm{Al}^{\mathrm{III}}$ substitution and the silanol groups, respectively. As $\mathrm{Co}^{\text {II }}$ ions were added to the synthesis gels, the resultant zeolite powders give an additional peak at $3619 \mathrm{~cm}^{-1}$, and its intensity is directly proportional to the cobalt loading. For the Co/ZSM-5 sample which was prepared by precipitating impregnation, Table 1 shows that its BET surface area was obviously lower than that of the pristine zeolite. This fact is attributed to either portions of the zeolitic structure were destructed or the pores were blocked.

The TPR profiles of Co-ZSM-5 samples with various cobalt loadings are shown in Fig. 2a-c. For Co-ZSM-5 of highest cobalt content (Fig. 2a), the TPR profile 
contains a small peak at $563 \mathrm{~K}$, and a strong peak with the maximum at $993 \mathrm{~K}$. The latter actually extends to temperatures higher than $1113 \mathrm{~K}$; in other words, the reduction was not complete even at $1113 \mathrm{~K}$. The integrated areas of both TPR peaks decrease as the cobalt content is lowered. The integrator sensitivity for the lowtemperature peak is eight times that of the high-temperature peak, and the area of the low-temperature peak is below $5 \%$ of the total area. Therefore, the species corresponding to low-temperature reduction are only a small portion of the CoZSM-5 samples. Moreover, these low-temperature peaks become very weak and nearly disappear for the samples with low cobalt content. Figs. $2 \mathrm{~b}$ and $2 \mathrm{c}$ show that only two weak broad peaks appear at ca. 523 and $693 \mathrm{~K}$, respectively.

The reduction behavior of Co-ZSM-5 was compared with that of the sample prepared by physically mixing $\mathrm{Co}_{3} \mathrm{O}_{4}$ and $\mathrm{H}-\mathrm{ZSM}-5$. Fig. $2 \mathrm{~d}$ shows that the TPR profile of the latter sample gives two peaks at around 593 and $703 \mathrm{~K}$. They are ascribed to the reduction of $\mathrm{Co}_{3} \mathrm{O}_{4}$ to $\mathrm{CoO}$ and that of $\mathrm{CoO}$ to Co metal, respectively. This result is consistent with the reduction behavior of bulk $\mathrm{Co}_{3} \mathrm{O}_{4}$ [11]. Accordingly, the small peak that appeared at $563 \mathrm{~K}$ in Co-ZSM-5 is likely due to the reduction of extra-framework cobalt oxide. Moreover, because this peak shifts to a lower temperature in comparison with that of the bulk $\mathrm{Co}_{3} \mathrm{O}_{4}$, the extra-framework cobalt oxide is probably in the form of very fine particles. On the other hand, the species reduced at ca. $993 \mathrm{~K}$ is attributed to framework cobalt or some other types of cobalt silicate since Roe et al. [12] reported that cobalt silicate required a temperature above $973 \mathrm{~K}$ to be reduced.

Fig. 2e shows the TPR profile of Co/ZSM-5 prepared by precipitating cobalt oxide onto ZSM-5 in alkaline solution. Surprisingly, the profile is very similar to that of Co-ZSM-5: a sharp peak at $973 \mathrm{~K}$ and a weak peak at $503 \mathrm{~K}$. However, an additional peak raises around $1043 \mathrm{~K}$ with a maximum at ca. $1111 \mathrm{~K}$. Puskas et al. [13] studied the system where cobalt oxide was precipitated on high surface area silica by neutralization of a nitrate solution. They found that cobalt silicates were formed and their reduction required temperatures higher than $973 \mathrm{~K}$. Therefore, the species which were reduced at $973 \mathrm{~K}$ and $1111 \mathrm{~K}$ probably correspond to two kinds of cobalt silicates, which were formed by cobalt ions reacting with ZSM-5 framework in the precipitation impregnation process. On the other hand, the amount of cobalt oxide which should be reduced at low temperature (ca. $503 \mathrm{~K}$ ) is only negligible.

In order to identify further the cobalt species in these samples, the X-ray diffraction (XRD) patterns and IR spectra of the samples reduced at various temperatures were examined. Fig. 3 shows the XRD patterns of Co-ZSM-5 ( $\mathrm{Si} / \mathrm{Co} \mathrm{mol}$ ratio $=5.4$ ) before and after reduction. The pattern before reduction is consistent with that of plain ZSM-5 with the intensity of the diffraction peaks being slightly weaker (Fig. 3a). In other words, the crystallinity of Co-ZSM-5 is somewhat lower than that of plain ZSM-5. Nevertheless, cobalt oxide was not detected in the pattern. The XRD pattern was hardly changed after Co-ZSM-5 was reduced at $793 \mathrm{~K}$, but the intensity of the diffractogram decreased dramatically after $1023 \mathrm{~K}$ reduction 


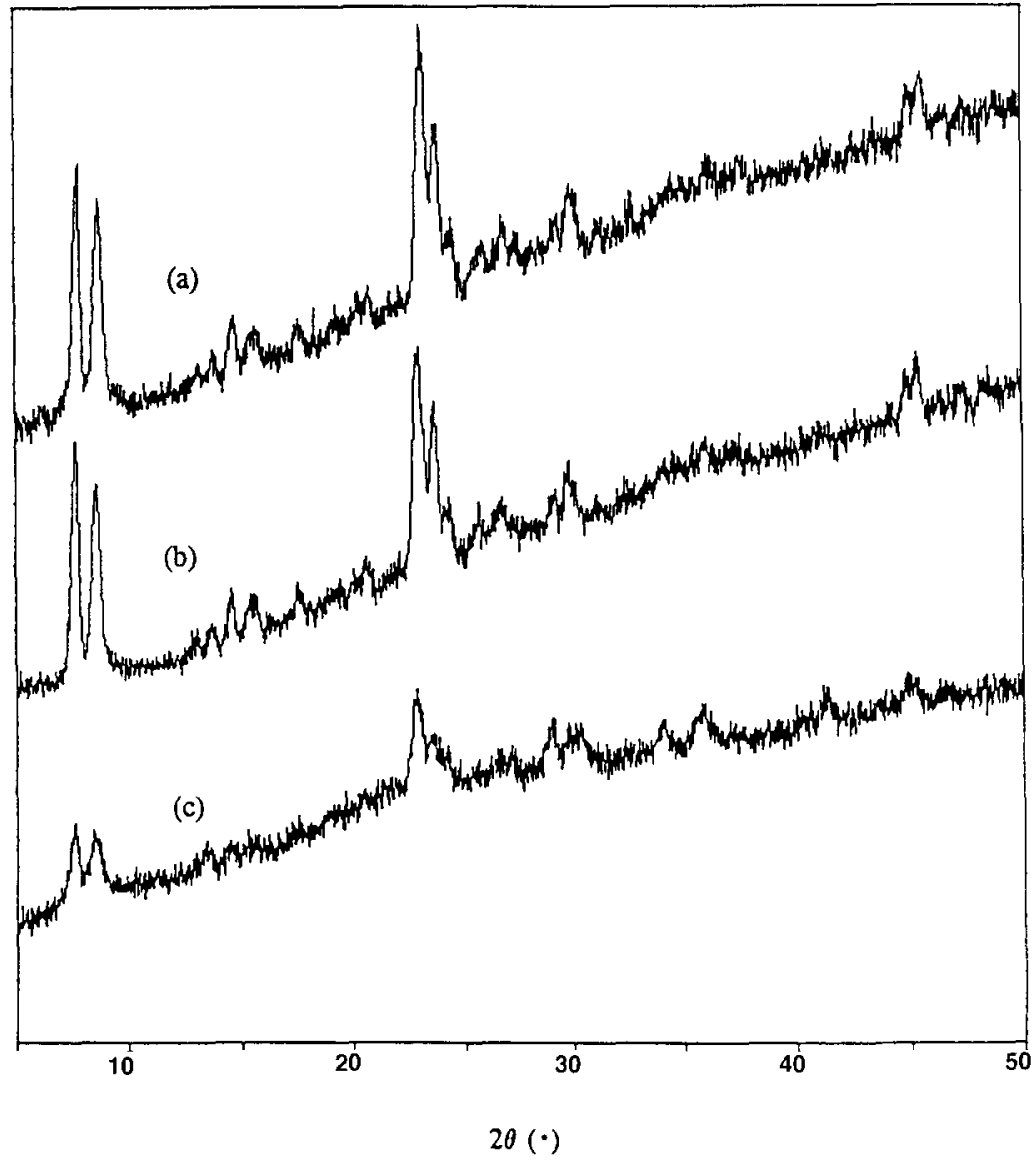

Fig. 3. XRD patterns of Co-ZSM-5 $(\mathrm{Si} / \mathrm{Co}=5.4)$ before (a), and after reduction at $793 \mathrm{~K}$ (b) and $1023 \mathrm{~K}$ (c)

(Fig. 3b and 3c, respectively). Therefore, the species which was reduced at 1023 $\mathrm{K}$ is likely to be cobalt incorporated in ZSM-5 framework. As cobalt was removed from the framework during the high-temperature reduction process, the zeolitic structure was largely broken down.

Fig. 4 shows the corresponding IR spectra of Co-ZSM-5 before and after reduction in comparison with those of $\mathrm{Co}_{3} \mathrm{O}_{4}$ and $\mathrm{H}-\mathrm{ZSM}-5$. The absorptions near 1100 , 800 , and $450 \mathrm{~cm}^{-1}$ are typical for high siliceous materials. According to the Flanigen-Khatami-Szymanski correlation $[14,15]$, these peaks were assigned to internal vibration of $\mathrm{Si}, \mathrm{AlO}_{4}$ tetrahedra and were common to silica and quartz. The absorption at $650-550 \mathrm{~cm}^{-1}$, on the other hand, was assigned to the presence of a double-ring of tetrahedra in the zeolitic framework [16]. For a ZSM-5 structure, the latter absorption appears near $550 \mathrm{~cm}^{-1}$. The intensity ratio of the peaks at 550 $\mathrm{cm}^{-1}$ to $450 \mathrm{~cm}^{-1}$ is often used as a quantitative measurement of zeolite crystallinity [12]. For Co-ZSM-5 before reduction, a peak appeared at ca. $665 \mathrm{~cm}^{-1}$, which is coincident with a strong absorption of $\mathrm{Co}_{3} \mathrm{O}_{4}$. This peak nearly disappeared after the sample was reduced at $793 \mathrm{~K}$ (Fig. 4c), and completely disappeared after 


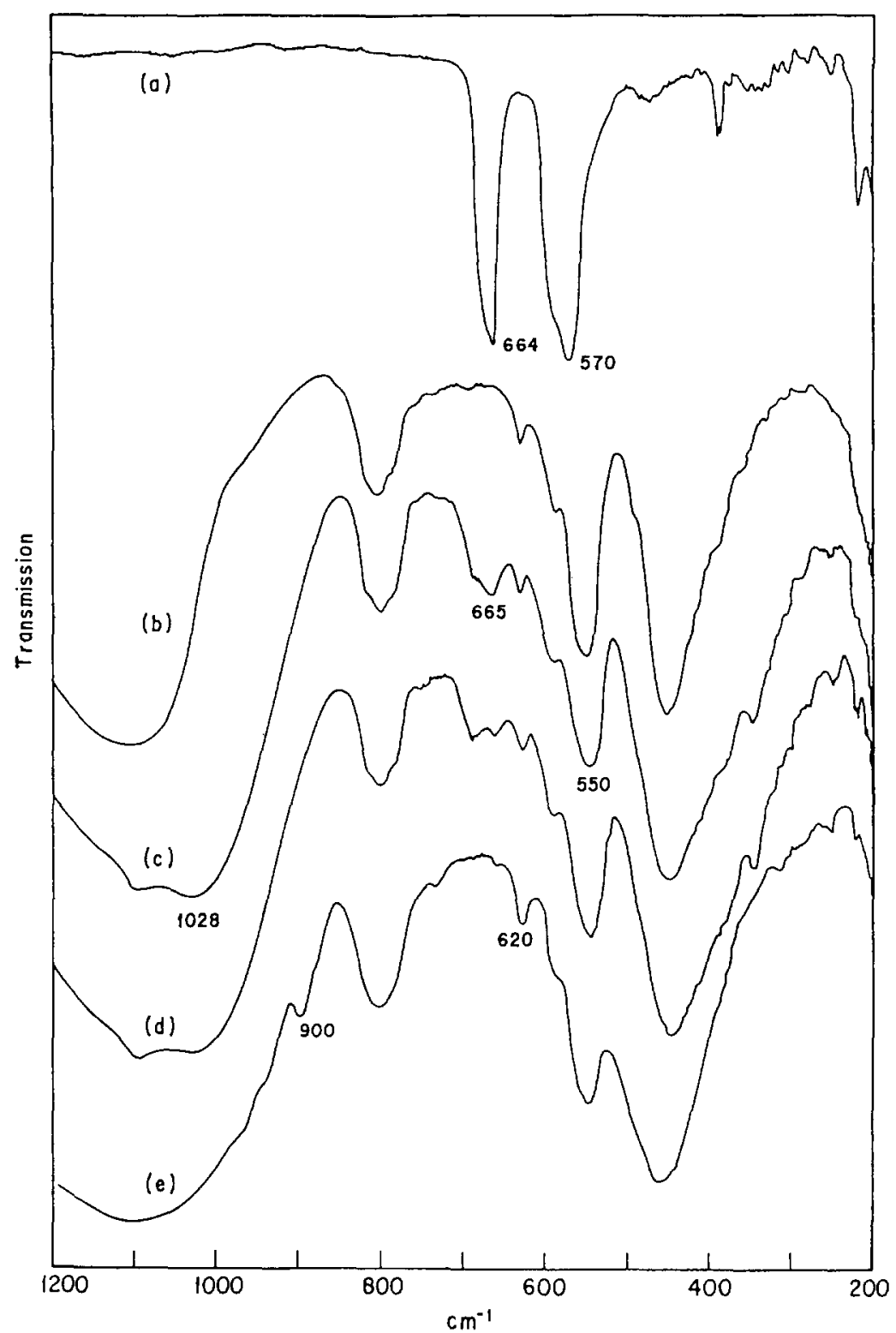

Fig. 4. IR spectra of $\mathrm{CO}_{3} \mathrm{O}_{4}(\mathrm{a})$; H-ZSM-5 (b); and Co-ZSM-5 ( $\left.\mathrm{Si} / \mathrm{Co}=5.4\right)$ before TPR (c), and after reduction at $793 \mathrm{~K}$ (d) and $1023 \mathrm{~K}$ (e).

reduction at $1023 \mathrm{~K}$ (Fig. $4 \mathrm{~d}$ ). Under the latter conditions, the bands at 1100 and $450 \mathrm{~cm}^{-1}$ became broad and the absorption at $620 \mathrm{~cm}^{-1}$ was enhanced. The peak at $620 \mathrm{~cm}^{-1}$ was considered one of the characteristic absorptions of cristobalite (a low symmetry $\mathrm{SiO}_{2}$ ) [17]. These results concordantly indicate the destruction of the ZSM-5 structure after Co-ZSM-5 was reduced at $1023 \mathrm{~K}$, and are also consistent with the XRD measurement. 
In comparison with the IR spectrum of ZSM-5 zeolite in the $\mathrm{Si}-\mathrm{O}$ stretching vibration region, the unreduced Co-ZSM-5 sample has an extra shoulder at ca. 1028 $\mathrm{cm}^{-1}$, which was retained after $793 \mathrm{~K}$ reduction. This $1028 \mathrm{~cm}^{-1}$ peak was also observed by Puskas et al. [13] in the silica supported cobalt system. It was assigned to authentic $\mathrm{CO}_{2} \mathrm{SiO}_{4}$. However, the presence of $\mathrm{Co}_{2} \mathrm{SiO}_{4}$ in Co-ZSM-5 zeolites is not likely because surface area data show no blockage of the zeolite pores. The $1028 \mathrm{~cm}^{-1}$ band is thus proposed due to cobalt substituted in zeolite framework. After reduction at $1023 \mathrm{~K}$, the absorption in the $\mathrm{Si}-\mathrm{O}$ stretching vibration region becomes very broad and two new peaks appear at ca. 900 and $935 \mathrm{~cm}^{-1}$. The two new peaks are consistent with the strongest absorption observed in cobalt orthosilicate [17]. Therefore, it is proposed that some cobalt orthosilicate is formed during the high-temperature reduction process and that it is never being completely reduced.

Fig. 5a and 5b compare the XRD patterns of H-ZSM-5 before and after cobalt oxide being precipitated onto it. Both patterns are typical for ZSM-5, but the intensity for Co/ZSM-5 is apparently lower. Accordingly, the structure of ZSM-5 was somewhat damaged during the preparation procedure. In other words, cobalt ions reacted with the zeolitic framework in alkaline medium at 358-363 K. That also accounts for the decrease in surface area of Co/ZSM-5 as compared with that of pristine ZSM-5. After reduction at $793 \mathrm{~K}$ and $1023 \mathrm{~K}$, both the structure and crystallinity of Co/ZSM-5 were found to be unchanged (Fig. 5c and 5d). These results are quite different from that observed on Co-ZSM-5, where the zeolite structure is seriously damaged after reduction at $1023 \mathrm{~K}$. The corresponding IR spectra of Co/ZSM-5 reduced at different temperatures are shown in Fig. 6. Fig. $6 \mathrm{a}$ is that of Co/ZSM-5 calcined at $823 \mathrm{~K}$ and before reduction. The absorption at $665 \mathrm{~cm}^{-1}$ was very weak, indicating that there was only a very small amount of $\mathrm{Co}_{3} \mathrm{O}_{4}$ in the precipitated sample. In the $\mathrm{Si}-\mathrm{O}$ stretching vibration region, a shoulder around $1028 \mathrm{~cm}^{-1}$ was also observed, although it is not as intense as that on CoZSM-5. That is also consistent with the results obtained from XRD and TPR experiments, which show that cobalt is mainly in some forms of cobalt silicate. After the sample was reduced at $793 \mathrm{~K}$, its IR spectrum was virtually unchanged (Fig. 6b), but when the reduction temperature was raised to $1023 \mathrm{~K}$, the small absorption at $665 \mathrm{~cm}^{-1}$ disappeared, the shoulder at $1028 \mathrm{~cm}^{-1}$ vanished, and the band at $1100 \mathrm{~cm}^{-1}$ became narrower (Fig. 6c). Actually, the spectrum is very similar to that of pristine ZSM-5. Accordingly, it is proposed that the cobalt atoms in Co/ZSM-5 are attached to the zeolite framework through bonding with two or three oxygen atoms. The assemblies may be in the form of (I) or (II) 


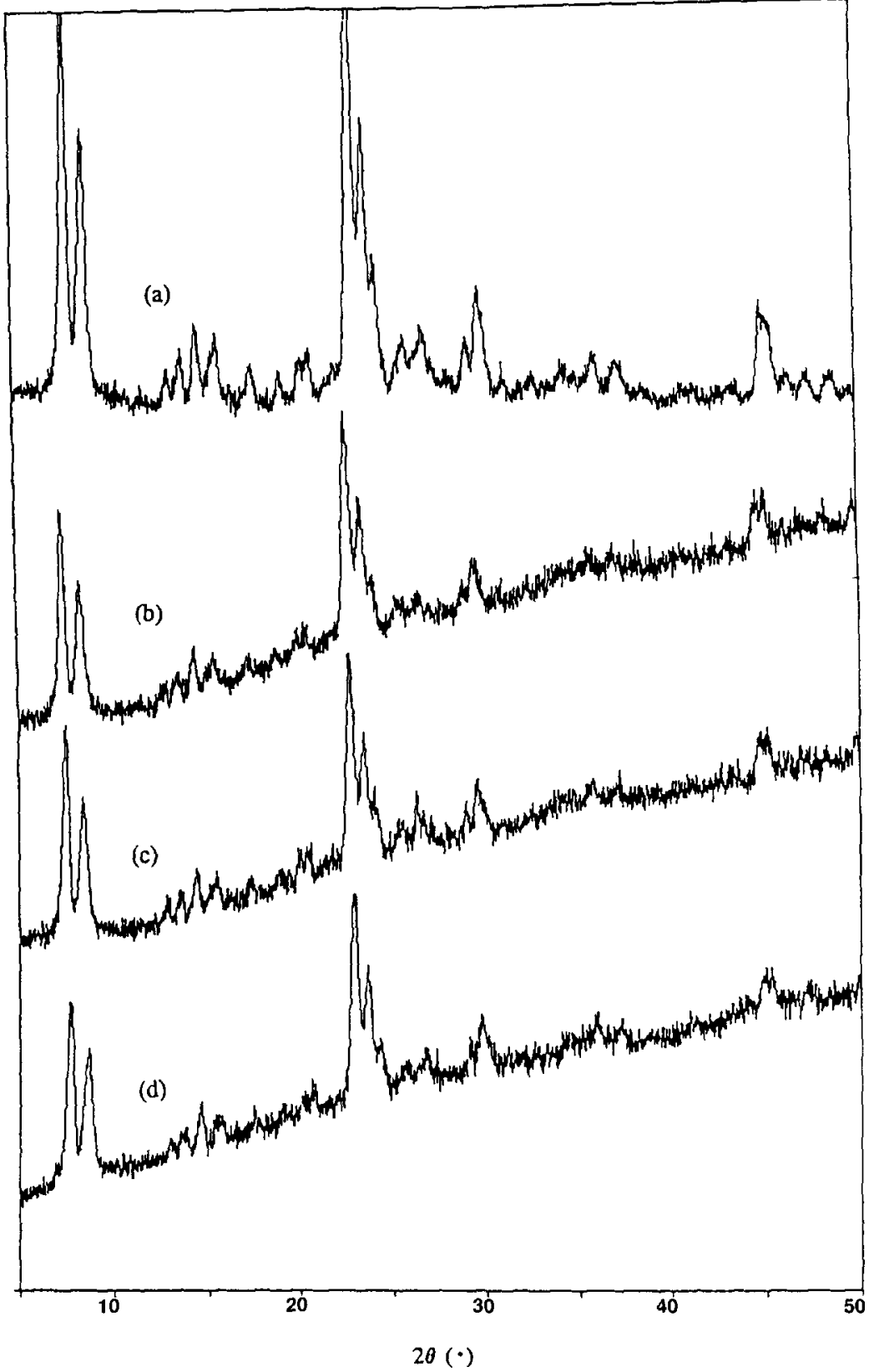

Fig. 5. XRD patterns of H-ZSM-5 (a); and Co/ZSM-5 before (b), and after reduction at $793 \mathrm{~K}$ (c) and $1023 \mathrm{~K}$ (d). 


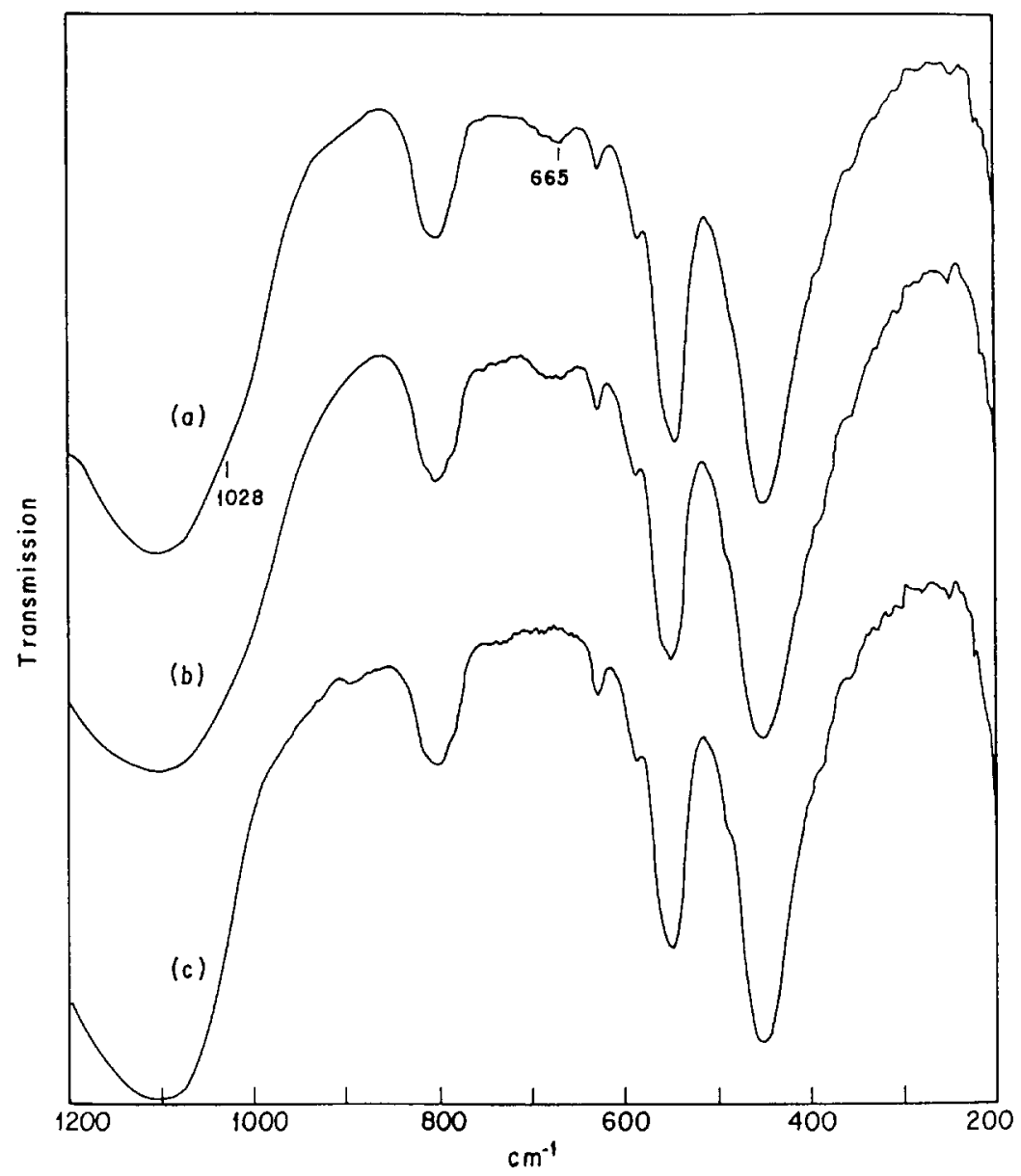

Fig. 6. IR spectra of Co/ZSM-5 before (a), and after reduction at $793 \mathrm{~K}(\mathrm{~b})$ and $1023 \mathrm{~K}$ (c) .

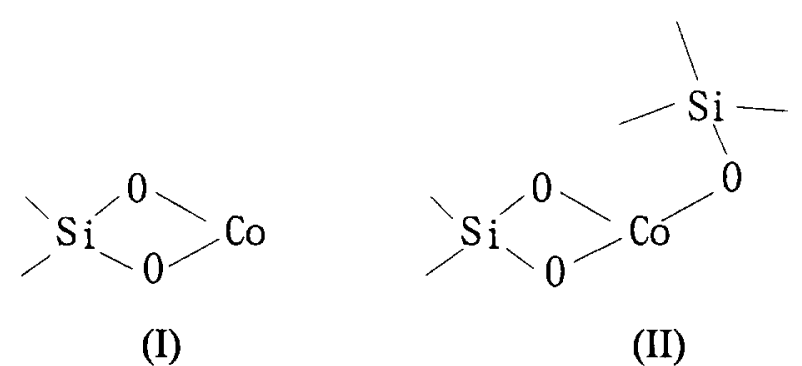

Their formation involves the break-down of portions of the zeolitic structure and their chemical properties are more like cobalt silicate than ion-exchanged cobalt. After reduction at $1023 \mathrm{~K}$, cobalt was removed from these assemblies, and the zeolitic framework, which had been partially destroyed during impregnation, was retained. 


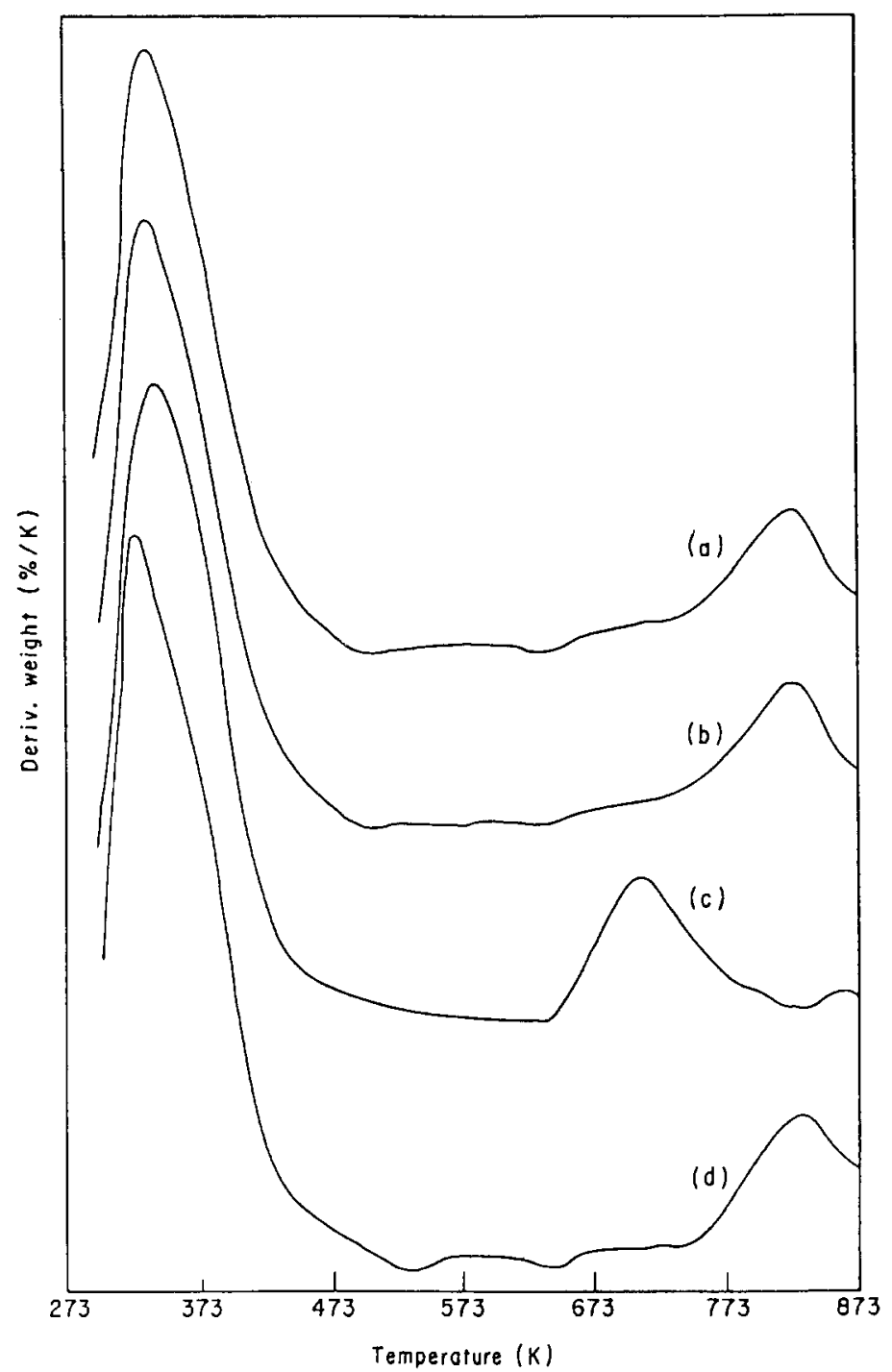

Fig. 7. TPD profiles of H-ZSM-5 (a), Co-ZSM-5 ( $\mathrm{Si} / \mathrm{Co}=27$ ) (b), $\mathrm{Co}-\mathrm{ZSM}-5$ ( $\mathrm{Si} / \mathrm{Co}=5.4)$ (c), and $\mathrm{Co}$ / ZSM-5 (d).

The acidity of the catalysts was examined by carrying out temperature-programmed desorption of ammonia (Fig. 7). The desorption bands that appeared at temperatures lower than $473 \mathrm{~K}$ are attributed to physically adsorbed ammonia, and that at ca. $825 \mathrm{~K}$ is due to ammonia desorbed from the strongly acidic sites of ZSM5. The TPD profile of Co/ZSM-5 is very similar to that of H-ZSM-5. In other words, the acidity of the sample was retained through the cobalt impregnation and $\mathrm{H}^{+}$-re-exchange processes. On the other hand, Co-ZSM-5 with low cobalt content $(\mathrm{Si} / \mathrm{Co}=27)$ gives a similar TPR profile as that of H-ZSM-5. However, for CoZSM-5 with high cobalt content $(\mathrm{Si} / \mathrm{Co}=5.4)$, the desorption band was found to shift to lower temperature, ca. $710 \mathrm{~K}$. Therefore, the latter catalyst has a lower 
Table 3

Carbon monoxide hydrogenation over cobalt containing ZSM-5 zeolites

\begin{tabular}{|c|c|c|c|c|c|}
\hline Catalysts & $\mathrm{Co}$ & Co/ZSM-5/PM & $\mathrm{Co} / \mathrm{ZSM}-5$ & \multicolumn{2}{|c|}{ Co-ZSM-5 } \\
\hline $\mathrm{Si} / \mathrm{Co}$ & & & & (5.4) & (27) \\
\hline $\mathrm{CO}$ conversion $(\mathrm{mol}-\%)$ & 93.6 & 94.0 & 3.6 & 41.9 & 0.7 \\
\hline \multicolumn{6}{|l|}{ Selectivity (mol-\%) } \\
\hline $\mathrm{CH}_{n}$ & 64.1 & 64.5 & 91.5 & 64.4 & 88.5 \\
\hline $\mathrm{CO}_{z}$ & 35.9 & 35.5 & 8.5 & 35.6 & 11.5 \\
\hline \multicolumn{6}{|l|}{$\mathrm{CH}_{n}$ composition (wt. $\left.-\%\right)$} \\
\hline $\mathrm{C}_{1}$ & 59.2 & 62.6 & 48.9 & 40.3 & 51.3 \\
\hline $\mathrm{C}_{2}$ & 9.9 & 9.0 & 22.9 & 5.2 & 21.4 \\
\hline $\mathrm{C}_{3}$ & 5.4 & 9.6 & 15.1 & 9.0 & 12.8 \\
\hline $\mathrm{C}_{4}$ & 5.4 & 6.8 & 4.3 & 7.8 & 1.8 \\
\hline $\mathrm{C}_{5+}$ & 17.2 & 1.6 & 7.3 & 37.5 & 3.5 \\
\hline Aromatics & - & 10.4 & 1.5 & 0.3 & 9.2 \\
\hline Wax & 0.1 & - & - & - & - \\
\hline \multicolumn{6}{|c|}{ Gasoline range composition (wt.- $\%$ ) } \\
\hline $\mathrm{C}_{5}$ & 24.8 & 18.1 & 31.5 & 16.5 & 8.1 \\
\hline $\mathrm{C}_{6}$ & 17.1 & 8.2 & 13.0 & 19.2 & 4.8 \\
\hline $\mathrm{C}_{7}$ & 15.8 & 2.1 & 11.5 & 17.8 & 14.6 \\
\hline $\mathrm{C}_{\mathrm{H}+}$ & 42.3 & 4.4 & 26.9 & 45.8 & - \\
\hline Benzene & - & 3.7 & 0.3 & - & 3.0 \\
\hline Toluene & - & 14.0 & 1.7 & 0.1 & 12.9 \\
\hline$m, p$-Xylene & - & 14.8 & 10.8 & 0.3 & 42.0 \\
\hline$o$-Xylene & - & 4.8 & 0.1 & - & 0.5 \\
\hline $\mathrm{tmb}^{\mathrm{a}}$ & - & 14.6 & 0.4 & 0.3 & - \\
\hline Ethyltoluene & - & 15.3 & 3.8 & - & 14.0 \\
\hline
\end{tabular}

Reaction conditions: $300^{\circ} \mathrm{C}, 50 \mathrm{~atm}, \mathrm{H}_{2} / \mathrm{CO}=1,1 \mathrm{~g}$ catalyst, flow-rate: $20 \mathrm{~cm}^{3} / \mathrm{min}$.

${ }^{\text {a }}$ Trimethylbenzene.

acidity compared to the other three catalysts. On the other hand, there is no direct correlation between the acidity and the aluminum content in the zeolites.

The catalytic activities of the bifunctional catalysts, Co-ZSM-5 and Co/ZSM-5, in carbon monoxide hydrogenation were compared with that of a cobalt and ZSM5 admixture (in 1:10 ratio, briefly termed as Co/ZSM-5/PM) as well as pure cobalt. Table 3 shows that the admixed catalyst has a higher carbon monoxide conversion than the catalysts prepared either by impregnating precipitation or coprecipitation. Because the TPR experiment shows that predominant cobalt species in the latter are not reducible under the reaction conditions, the low carbon monoxide conversion is attributed to the lower amount of metallic cobalt present in the catalysts. For Co-ZSM-5 of higher cobalt loading $(\mathrm{Si} / \mathrm{Co}=5.4$ ), the presence of easily reduced extra-framework cobalt oxide is confirmed by the high carbon monoxide conversion.

The product distributions are very much different for catalysts from different preparation methods. Wax, which was detected on unsupported cobalt catalyst, vanished completely when ZSM-5 was added by any of the mentioned methods to 
form bifunctional catalysts. This result is ascribed to the shape selectivity and acidic function of ZSM-5. Aromatic products are remarkably enhanced when cobalt was physically mixed with H-ZSM-5. A similar enhancement in aromatics formation was observed over Co-ZSM-5 of low cobalt loading ( $\mathrm{Si} / \mathrm{Co}=27$ ), as the TPD of ammonia experiment shows that the acidity of the latter is similar to that of $\mathrm{H}$ ZSM-5. As to Co-ZSM-5 of high cobalt loading ( $\mathrm{Si} / \mathrm{Co}=5.4$ ), which shows a lower acidity in TPD of ammonia, the aromatics selectivity is very low. Therefore, strong acid sites are responsible for the aromatics formation.

Although Co/ZSM-5 and Co-ZSM-5 ( $\mathrm{Si} / \mathrm{Co}=27)$, both have a similarly low carbon monoxide conversion and high acidity, the hydrocarbon product distributions are very different. Over the former catalyst, the aromatics selectivity is low, and pentane is the main component of the liquid products $(31.5 \%)$. The shift of liquid products towards lower molecular weight is attributed to the shape selectivity of the narrower pore windows in the zeolite, which is a result of the attachment of cobalt silicate-assemblies to the zeolite framework.

\section{Conclusions}

From the experimental results, it is concluded that cobalt can be highly dispersed in zeolite matrix either through incorporation of cobalt into the zeolite synthesis gel, or by precipitating cobalt oxide onto zeolite in alkaline solution. However, the resultant cobalt species are very different. From the structural characterization and TPR experiments, it was found that the main cobalt species in the co-precipitation catalysts (Co-ZSM-5) are cobalt substituted in ZSM-5 framework. Extra-framework $\mathrm{Co}_{3} \mathrm{O}_{4}$ also exists as minor component, and its content increases with cobalt loading. For the precipitating impregnation catalyst (Co/ZSM-5), cobalt silicatelike assemblies attached to the ZSM-5 framework were found to be the predominant cobalt species formed, and only negligible amounts of $\mathrm{Co}_{3} \mathrm{O}_{4}$ were present. While cobalt oxide is easily reduced below $793 \mathrm{~K}$, framework cobalt and cobalt silicate assemblies need temperatures higher than $993 \mathrm{~K}$ to be reduced. Reduction of framework cobalt is accompanied with the destruction of the ZSM-5 lattice in CoZSM-5. However, the zeolitic structure is hardly affected through the reduction of cobalt silicate assemblies in Co/ZSM-5.

In carbon monoxide hydrogenation, only zero-valence cobalt is the active species. Because both $\mathrm{Co}-\mathrm{ZSM}-5(\mathrm{Si} / \mathrm{Co}=27)$ and $\mathrm{Co} / \mathrm{ZSM}-5$ were hardly reduced under the pretreatment conditions, they showed low catalytic activities. Increasing the cobalt loading in Co-ZSM-5 increased the amount of reducible cobalt oxide in the catalyst. As a result, the conversion was increased, and non-aromatic gasoline range products became predominant. The low selectivity of aromatic products is attributed to the weaker acidity of the catalyst. In contrast, the physically admixed sample has the greatest amount of reducible $\mathrm{Co}_{3} \mathrm{O}_{4}$ and strong acidity from $\mathrm{H}$ - 
ZSM-5; therefore it gives the highest activity as well as highest selectivity of aromatics products.

\section{Acknowledgements}

Financial support from the National Science Council of the Republic of China is gratefully acknowledged. The authors also like to extend the acknowledgement to the technical lab of Mac Science, Japan for their kind help in determining the lattice parameters.

\section{References}

[1] J. Turkevich, Catal. Rev.-Sci. Eng., 1 (1967) 1.

[2] Y. Ono, Stud. Surf. Sci. Catal., 54 (1990) 185.

[3] C.D. Chang, W.H. Lang and A.J. Silvestri, J. Catal., 56 (1979) 268.

[4] P.D. Caeser, J.A. Brennan, W.E. Garwood and J. Ciric, J. Catal., 56 (1979) 274.

[5] U.S. Rao and R.J. Gormley, Hydrocarbon Process., 59 (1980) 139

[6] R. Szostak, V. Nair. D.K. Simmons, T.L. Thomas, R. Kuvadia, B. Dunson and D.C. Shieh, Stud. Surf. Sci. Catal., 37 (1988) 403 .

[7] D.K. Lee and S.K. Ihm, Appl. Catal., 32 (1987) 85.

[8] A. Shamsi, U.S. Rao, R.J. Gormley, R.T. Obermyer, R.R. Schehl and J.M. Stencel, Ind. Eng. Chem. Prod. Res. Dev., 23 (1984) 513.

[9] J.A. Rossin, C. Saldarriaga and M.E. Davis, Zeolites, 7 (1987) 295.

[10] N.Y. Chen, J.N. Miale and W.J. Reagan. US Patent 4112056 (1978).

[11] T. Paryjczak, J. Rynkowski and S.J. Karski, J. Chromatogr., 188 (1980) 254.

[12] G.M. Roe, M.J. Kidd, K.J. Cavell and F.P. Larkin, Stud. Surf. Sci. Catal., 36 (1988) 509

[13] I. Puskas, T.H. Fleisch, J.B. Hall, B.L. Meyers and R.T. Roginski, J. Catal., 134 (1992) 615.

[14] E.M. Flanigen, H. Khatami and H. Szymanski, Adv. Chem. Ser., 101 (1971) 201

[15] E.M. Flanigen, in J.A. Rabo (Editor), Zeolite Chemistry and Catalysis, Am. Chem. Soc., Washington, 1976, p. 80.

[16] G. Coudurier, C. Naccache and J.C. Vedrine, J. Chem. Soc., Chem. Commun., (1982) 1413.

[17] R.A. Nyquist and R.O. Kagel (Editors), Infrared Spectra of Inorganic Compounds, Academic Press. New York and London, 1971. 